\title{
Vibrio cholerae 0139 requires neither capsule nor LPS O side chain to grow inside Acanthamoeba castellanii
}

Correspondence

Gunnar Sandström

gunnar.sandstrom@smi.se

Received 3 July 2008

Accepted 5 September 2008

\author{
Hadi Abd, ${ }^{1}$ Amir Saeed, ${ }^{1,2}$ Andrej Weintraub ${ }^{2}$ and Gunnar Sandström ${ }^{1,2}$ \\ ${ }^{1}$ Centre for Microbiological Preparedness, Swedish Institute for Infectious Disease Control, SE-171 \\ 82 Solna, Sweden \\ ${ }^{2}$ Division of Clinical Microbiology, Department of Laboratory Medicine, Karolinska Institute, \\ Karolinska University Hospital Huddinge, SE-14186 Stockholm, Sweden
}

\begin{abstract}
Vibrio cholerae, the causative agent of cholera, has the ability to grow and survive in the aquatic free-living amoeba Acanthamoeba castellanii. The aim of the present study was to examine the ability of the clinical isolate $V$. cholerae $\mathrm{O} 139 \mathrm{MO} 10$ to grow in $A$. castellanii and to determine the effect of the bacterial capsule and LPS O side chain on intracellular growth. Results from cocultivation, viable counts, a gentamicin assay, electron microscopy and statistical analysis showed that the association of $V$. cholerae $0139 \mathrm{MO} 10$ with $A$. castellanii did not inhibit growth of the amoeba, and enhanced growth and survival of $V$. cholerae $0139 \mathrm{MO} 10$ occurred. The wild-type $V$. cholerae $\mathrm{O} 139 \mathrm{MO} 10$ and a capsule mutant or capsule/LPS double mutant grew inside $A$. castellanii. Neither the capsule nor the LPS O side chain of $V$. cholerae $\mathrm{O} 139$ was found to play an important role in the interaction with $A$. castellanii, disclosing the ability of $V$. cholerae to multiply and survive inside $A$. castellanii, as well as the role of $A$. castellanii as an environmental host for $V$. cholerae.
\end{abstract}

\section{INTRODUCTION}

Vibrio cholerae $\mathrm{O} 1$ and $\mathrm{O} 139$ have the ability to grow and survive inside the aquatic free-living amoeba Acanthamoeba castellanii (Abd et al., 2005, 2007). However, the involvement of macromolecules in this interaction has not been studied, and it is not known whether the capsule and LPS O side chain play a role in intracellular growth and survival of $V$. cholerae in A. castellanii.

$V$. cholerae O139, the causative agent of cholera, possesses a mannose-sensitive haemagglutinin fimbria (Chiavelli et al., 2001), a polysaccharide capsule (Johnson et al., 1994; Weintraub et al., 1994) and a LPS (Knirel et al., 1997). Both the capsule and LPS O side chain are considered virulence factors (Waldor et al., 1994) and have been found to be important factors for colonization in the mammalian intestine (Nesper et al., 2002). The LPS may function as an adhesion factor (Alam et al., 1997), and the capsule of $V$. cholerae $\mathrm{O} 139$ enhances intestinal colonization (Waldor et al., 1994). Moreover, it has been shown that the capsule of $V$. cholerae $\mathrm{O} 139$ tends to contribute to effective adherence to the human intestinal mucosa (Yamamoto et al., 1994) and to partial resistance to phagocytosis (Albert et al., 1999). It is known that the mannose-sensitive haemagglutinin fimbria of $V$. cholerae $\mathrm{O} 139$ contributes to its attachment to plankton in aquatic habitats (Chiavelli et al., 2001).
Lock et al. (1987) found that bacteria possessing mannosesensitive fimbriae were able to adhere to acanthamoebae or leukocytes. Both $V$. cholerae $\mathrm{O} 139$ and A. castellanii possess ligands and receptors for mannose (Dearborn \& Korn, 1974; Lock et al., 1987; Tarsi \& Pruzzo, 1999). It is well known that $A$. castellanii takes up bacteria via pseudopodia to form food vacuoles in which phagocytosis and digestion occur within phagolysosomes (Oates \& Touster, 1976).

The aim of the present study was to examine the ability of the clinical isolate $V$. cholerae $\mathrm{O} 139 \mathrm{MO} 10$ to grow in $A$. castellanii and to determine the role of the bacterial capsule and LPS in the intracellular growth of $V$. cholerae O139 MO10 in A. castellanii.

\section{METHODS}

Micro-organisms. A. castellanii was obtained from the American Type Culture Collection (ATCC 30010).

$V$. cholerae $\mathrm{O} 139 \mathrm{MO} 10$ is a wild-type strain producing a capsule and a short LPS O side chain. It is a clinical isolate and emerged in 1992 causing epidemic cholera in India. The MO10-T4 strain is a spontaneous capsule mutant of MO10 (Waldor et al., 1994). The Bengal-2R strain (capsule/LPS double mutant) is a negative transposon Tn5lac insertion mutant of Bengal-2 (Knirel et al., 1997), which is a vaccine derivative of MO10 (Waldor et al., 1994). Strains were obtained from the culture collection of the Laboratory Science Division, International Centre for Diarrhoeal Disease Research, Bangladesh. 
Culture media and growth conditions. $V$. cholerae MO10 strains were grown on blood agar plates for $24 \mathrm{~h}$ at $37{ }^{\circ} \mathrm{C}$. A. castellanii was grown at $30{ }^{\circ} \mathrm{C}$ to a final concentration of $10^{6}$ cells $\mathrm{ml}^{-1}$ in ATCC medium no. 712. To infect the amoebae, $V$. cholerae was grown in Luria-Bertani broth to an $\mathrm{OD}_{600}$ of 0.6 . Co-cultures of each bacterial strain and A. castellanii were incubated in $75 \mathrm{~cm}^{2}$ cell culture flasks (Corning Costar) filled with $50 \mathrm{ml}$ ATCC medium no. 712 containing an initial concentration of $10^{5}$ cells A. castellanii $\mathrm{ml}^{-1}$ and $10^{6}$ cells each bacterial strain $\mathrm{ml}^{-1}$. Control flasks containing bacteria or amoebae only were prepared in the same way and with the same initial concentration as the co-culture flasks. The flasks were incubated without shaking at $30{ }^{\circ} \mathrm{C}$. Samples were withdrawn regularly for microscopy, cell counts and viable counts.

The sensitivity of $V$. cholerae MO10 strains to gentamicin was determined by resuspending one bacterial colony in $1 \mathrm{ml}$ sterile PBS, following a 100-fold dilution in PBS. A cotton swab was soaked in the suspension and plated on blood agar plates. One gentamicin disc ( $30 \mu \mathrm{g}$; Sigma) was applied to the agar plate, and the plate was incubated for $24 \mathrm{~h}$ at $37^{\circ} \mathrm{C}$. Judgement of the gentamicin sensitivity of bacteria was carried out by measuring the diameter of inhibition of bacterial growth around the gentamicin disc. A diameter $\geqslant 21 \mathrm{~mm}$ was considered as the cut-off point for sensitivity.

V. cholerae strain association assays. To estimate the growth and survival of the $V$. cholerae MO10 strains in the presence or absence of A. castellanii by viable counts, $1 \mathrm{ml}$ from each bacterial control flask and from flasks containing both bacteria and amoebae was withdrawn. Viable counts were assessed by preparing 10-fold dilutions from $10^{-1}$ to $10^{-10}$ and spreading these on blood agar plates. All plates were incubated at $37^{\circ} \mathrm{C}$ for $24 \mathrm{~h}$.

Bacterial adherence assay. Co-cultures of V. cholerae MO10 strains with $A$. castellanii were incubated in $75 \mathrm{~cm}^{2}$ cell culture flasks filled with $50 \mathrm{ml}$ ATCC medium no. 712 containing $100 \mathrm{mM}$ mannose, an initial concentration of $10^{5}$ cells A. castellanii $\mathrm{ml}^{-1}$ and $10^{6}$ cells of each $V$. cholerae strain $\mathrm{ml}^{-1}$. Mannose-negative control flasks were prepared in the same way and with the same initial concentrations of co-cultivated micro-organisms but without mannose. The flasks were incubated without shaking at $30{ }^{\circ} \mathrm{C}$ and samples were withdrawn after $1 \mathrm{~h}$ to determine the percentage of bacteria adhered to the amoeba cells by dividing the number of amoebae with adhered bacteria by the total number of amoebae with and without adhered bacteria, multiplied by 100 .

Bacterial uptake, intracellular growth and survival. The ability of A. castellanii to take up $V$. cholerae MO10 strains and the effect of the capsule and LPS O side chain on the uptake and intracellular growth of the bacterial strains were examined by comparing the interactions of wild-type MO10 and the capsule mutant and capsule/LPS double mutant of the MO10 strain with the amoebae.

Co-cultures of each bacterial strain with $A$. castellanii were incubated in $75 \mathrm{~cm}^{2}$ cell culture flasks filled with $50 \mathrm{ml}$ ATCC medium no. 712 containing an initial concentration of $10^{5}$ cells A. castellanii $\mathrm{ml}^{-1}$ and $10^{6}$ cells each bacterial strain $\mathrm{ml}^{-1}$. The flasks were incubated without shaking at $30{ }^{\circ} \mathrm{C}$ for $2 \mathrm{~h}$. Each cell suspension was centrifuged for $10 \mathrm{~min}$ at $300 \mathrm{~g}$ in a Labofuge GL centrifuge (VWR International) and washed six times in PBS to remove non-adhered extracellular $V$. cholerae. The pellets were resuspended in $1 \mathrm{ml}$ PBS and incubated with $500 \mu \mathrm{g}$ gentamicin $\mathrm{ml}^{-1}$ for $1 \mathrm{~h}$ at room temperature. The samples were then diluted in $9 \mathrm{ml}$ PBS and centrifuged for $10 \mathrm{~min}$ at $300 \mathrm{~g}$. Each pellet was resuspended in a volume of $50 \mathrm{ml}$ in a culture flask filled with ATCC medium to analyse uptake, intracellular growth and survival of $V$. cholerae strains. One millilitre from each flask was centrifuged for $10 \mathrm{~min}$ at $300 \mathrm{~g}$ and each pellet was diluted twofold with $0.1 \%$ sodium deoxycholate to permeabilize the amoeba cells. A series of 10 -fold dilutions of the sample from $10^{-1}$ to $10^{-4}$ was prepared and spread on blood agar plates. All plates were incubated at $37{ }^{\circ} \mathrm{C}$ for $24 \mathrm{~h}$, and viable counts were performed for the engulfed bacteria. The reculture flasks were incubated without shaking at $30{ }^{\circ} \mathrm{C}$ to investigate the intracellular growth and survival of $V$. cholerae strains using a gentamicin assay and by viable counts for 14 days.

Effect of mannose on the uptake of $V$. cholerae 0139 MO10 in A. castellanii. The uptake of $V$. cholerae MO10 by A. castellanii in ATCC medium containing mannose was compared with uptake in a mannose-depleted medium to determine whether bacteria adhered to the amoebae specifically via mannose or non-specifically. Both interacting micro-organisms possess ligands and receptors for mannose; thus the addition of mannose to the culture medium should inhibit specific mannose-dependent adherence between the two micro-organisms, resulting in decreased uptake and hence growth of $V$. cholerae MO10 inside A. castellanii.

A. castellanii association assays. Viable acanthamoebae in the presence or absence of bacteria were counted in a Bürker chamber (Merck Eurolab) under a light microscope (Carl Zeiss) using basic erythrosin B staining (ATCC). The intracellular localization of each $V$. cholerae O139 strain was analysed by electron microscopy. Five millilitre samples from culture flasks containing amoebae in the presence of bacteria were centrifuged for $10 \mathrm{~min}$ at $300 \mathrm{~g}$. The resulting pellets were washed with PBS. Each pellet of infected amoebae was fixed in $2.5 \%$ glutaraldehyde in $0.1 \mathrm{M}$ sodium cacodylate buffer ( $\mathrm{pH} 7.3$ ), with $0.1 \mathrm{M}$ sucrose and $3 \mathrm{mM} \mathrm{CaCl}_{2}$, for $30 \mathrm{~min}$ at room temperature. Samples were then washed in sodium cacodylate buffer and post-fixed in $2 \%$ osmium tetroxide in the same buffer for $1 \mathrm{~h}$. The samples were centrifuged and the pellets were dehydrated and embedded in Epoxy resin (LX-112). The embedded samples were cut into ultrathin sections, placed on grids and stained with uranyl acetate and lead citrate. Sections were examined under a transmission electron microscope (Philips 420).

Statistical analysis. Student's $t$-test and a $\chi^{2}$ test were performed for comparative statistical analysis of growth of single and co-cultivated micro-organisms, as well as of intracellular MO10 strains, to show the role of the LPS and/or capsule of $V$. cholerae $\mathrm{O} 139$ in interactions with A. castellanii.

\section{RESULTS}

\section{Growth of $A$. castellanii in the presence or absence of $V$. cholerae}

To study the effect of $V$. cholerae on A. castellanii, growth of $A$. castellanii in the presence or absence of $V$. cholerae MO10 strains was studied by means of viable amoeba cell counts. The initial concentration of the amoebae (trophozoites and cysts) in the presence or absence of $V$. cholerae MO10 strains was $2 \times 10^{5} \mathrm{cells} \mathrm{ml}^{-1}$, and increased 10 -fold in the absence of the bacteria after 14 days.

The number of $A$. castellanii in the presence of wild-type $V$. cholerae MO10, the capsule mutant strain and the capsule/ LPS double mutant of the MO10 strain also increased 10fold (Fig. 1). Despite the number of amoebae in the presence of the capsule mutant strain, the number of amoebae was not as high as has been shown by counts in the presence of other bacterial strains. Growth of $A$. castellanii in the presence or absence of MO10 strains did not show any statistical significance $(t$-test, $P>0.05)$. 


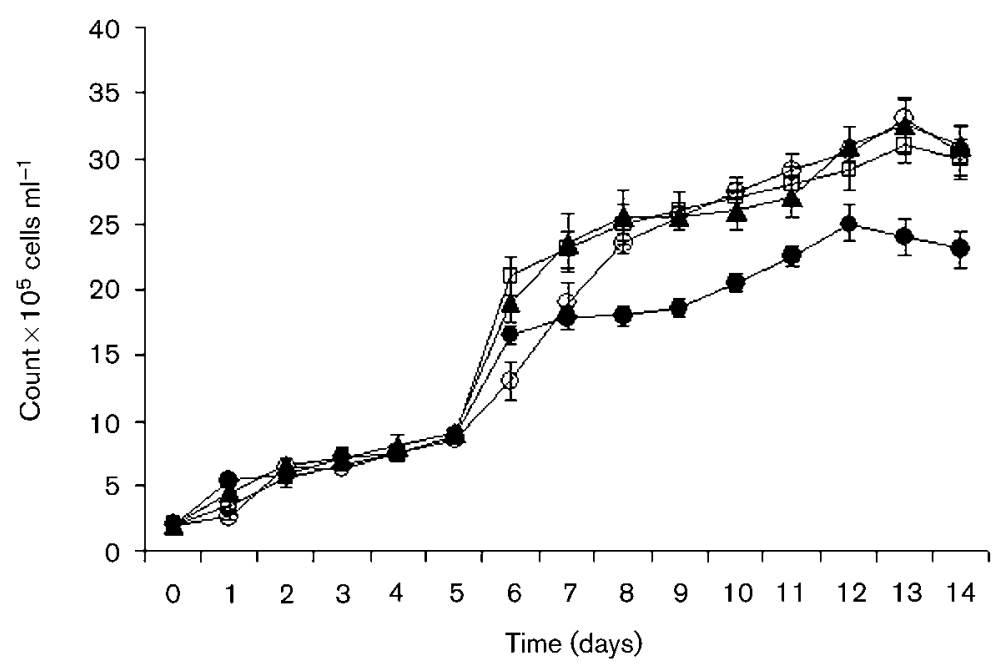

Fig. 1. Growth of $A$. castellanii. The numbers of $A$. castellanii in the presence of $V$. cholerae MO10 (A), V. cholerae MO10-T4 () or V. cholerae Bengal-2R $(\bigcirc)$, or in the absence of $V$. cholerae $(\square)$, are shown. The data indicate means $\pm S D$ of four repeated experiments at each time point. The results showed that growth of $A$. castellanii is triphasic, with a log phase, a stationary phase and the start of a decline in growth.

\section{Growth of $V$. cholerae in the presence or absence of A. castellanii}

To study the effect of $A$. castellanii on the growth and viability of $V$. cholerae strains, the growth and viability of $V$. cholerae strains cultivated alone in ATCC medium were compared with those of the same strains co-cultivated with amoebae in the same medium.

The viable counts of wild-type MO10, the capsule mutant strain and the capsule/LPS double mutant strain in the presence of A. castellanii showed 1000-, 1000- and 10-fold increases after 1 day, respectively, and all bacterial strains survived for more than 2 weeks (Fig. 2). Viable counts of all $V$. cholerae MO10 strains in the absence of amoebae increased 100-, 100- and 10-fold during the first day, respectively, followed by a decrease to non-detectable levels on days 4 and 5 (Fig. 2). Student's $t$-test showed a significant statistical difference in the growth of bacteria in the presence or absence of $A$. castellanii $(P<0.0001)$.

\section{Adherence between A. castellanii and $V$. cholerae M010 strains}

To estimate the effect of mannose on the adherence of wild-type MO10, the capsule mutant strain and the capsule/LPS double mutant strain to amoeba cells, the percentage of each bacterial strain adhering to A. castellanii in the presence or absence of mannose was determined and found to be $95 \pm 1.0,98 \pm 1.5$ and $93 \pm 1.0$, and $96 \pm 2.0$, $99 \pm 1.5$ and $95 \pm 1.5 \%$, respectively. It was found that each amoeba cell had between one and five adhered bacteria. Moreover, adherence was not statistically significantly affected by mannose ( $t$-test, $P=0.999$ ).

\section{Uptake of $V$. cholerae MO10 strains by A. castellanii}

To investigate the effect of the capsule or LPS on the uptake of bacteria, the number of engulfed wild-type

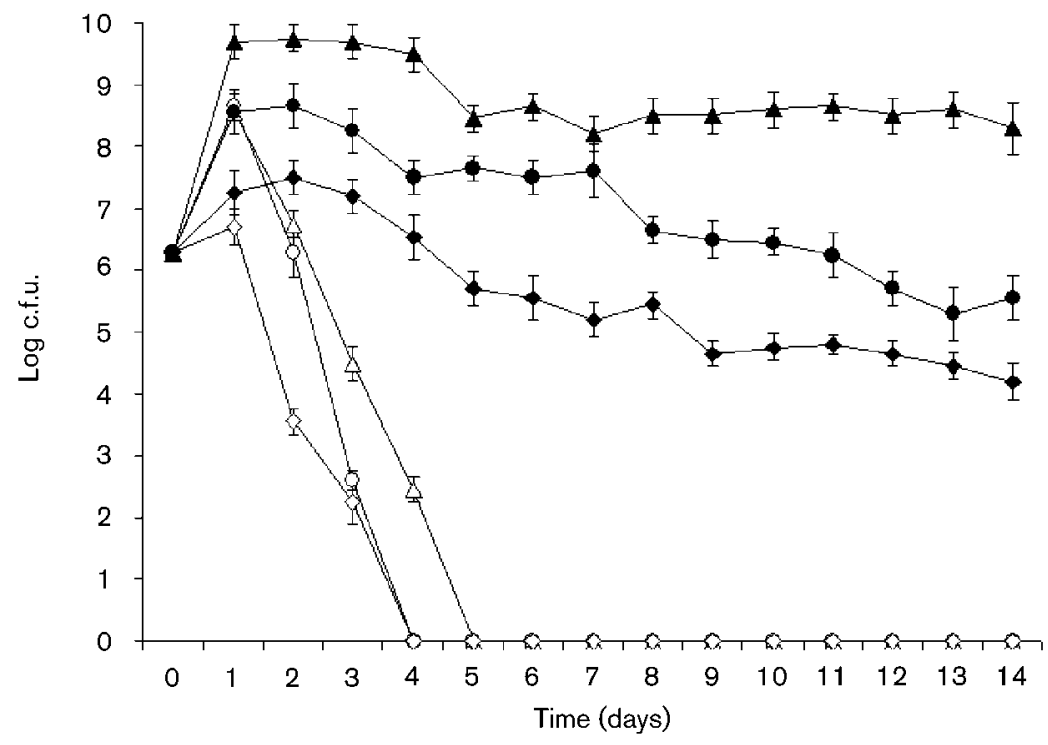

Fig. 2. Growth of $V$. cholerae. The numbers of viable $V$. cholerae are shown in the absence (open symbols) and presence (filled symbols) of $A$. castellanii for $V$. cholerae strains $\mathrm{MO} 10$ $(\triangle, \boldsymbol{\Delta})$, MO10-T4 $(\bigcirc, \boldsymbol{\bullet})$ and Bengal-2R $(\diamond, \diamond)$. The data indicate means \pm SD of three repeated experiments at each time point. 


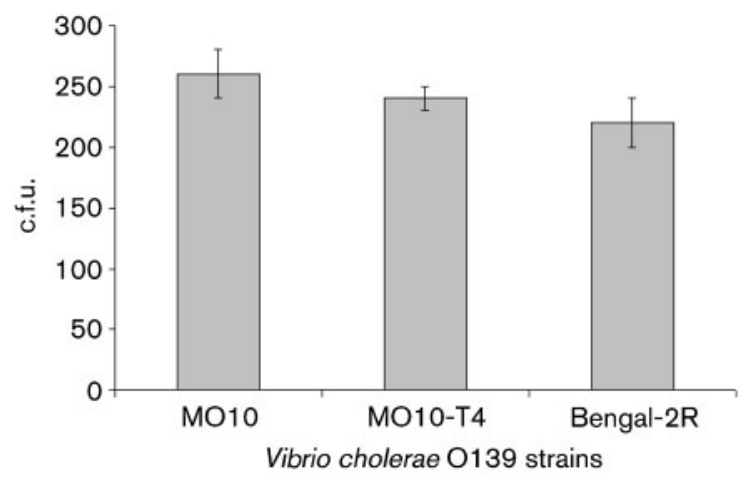

Fig. 3. Uptake of $V$. cholerae by $A$. castellanii. The number of engulfed $V$. cholerae MO10, MO10-T4 and Bengal-2R was estimated by viable count and gentamicin assay after $2 \mathrm{~h}$ of cocultivation. The data indicate means $\pm S D$ of three repeated experiments at each time point.

MO10, capsule mutant and capsule/LPS double mutant strains was estimated by viable counts and by gentamicin assay after $2 \mathrm{~h}$ of co-cultivation and found to be $2.6 \times 10^{2} \pm 20, \quad 2.4 \times 10^{2} \pm 10$ and $2.2 \times 10^{2} \pm 20$ c.f.u. $\mathrm{ml}^{-1}$, respectively. The differences in the uptake of the $V$. cholerae strains were not statistically significant $\left(\chi^{2}\right.$ test, $P=0.99$ ) (Fig. 3).

\section{Effect of mannose on the uptake of $V$. cholerae M010}

To study the effect of mannose on the uptake of the wildtype $V$. cholerae MO10 strain, uptake of MO10 by $A$. castellanii was compared in the presence and absence of mannose. The viable count of engulfed $V$. cholerae MO10 in the presence or absence of mannose after $2 \mathrm{~h}$ of cocultivation was $4.0 \times 10^{2} \pm 20$ and $2.9 \times 10^{2} \pm 10$ c.f.u. $\mathrm{ml}^{-1}$, respectively. The uptake of $V$. cholerae MO10 in the presence or absence of mannose was not significantly different $\left(\chi^{2}\right.$ test, $P=0.999$ ), thus excluding a role of mannose in the $V$. cholerae- $A$. castellanii interaction.

\section{Intracellular growth and survival of engulfed $\boldsymbol{V}$. cholerae M010 strains}

To estimate the growth and survival of the engulfed bacteria following gentamicin treatment and recultivation, the number of bacteria growing intracellularly was estimated by viable counts.

Viable counts of engulfed wild-type MO10, capsule mutant and capsule/LPS double mutant strains increased intracellularly to $10^{3}$ c.f.u. $\mathrm{ml}^{-1}$ after $24 \mathrm{~h}$ and to $10^{5}$ c.f.u. $\mathrm{ml}^{-1}$ after $48 \mathrm{~h}$, and the engulfed bacteria survived at $10^{5}$ c.f.u. $\mathrm{ml}^{-1}$ for more than 2 weeks (Fig. 4). A $\chi^{2}$ test did not show any statistical differences in the intracellular growth of the $V$. cholerae strains $(P=0.999)$.

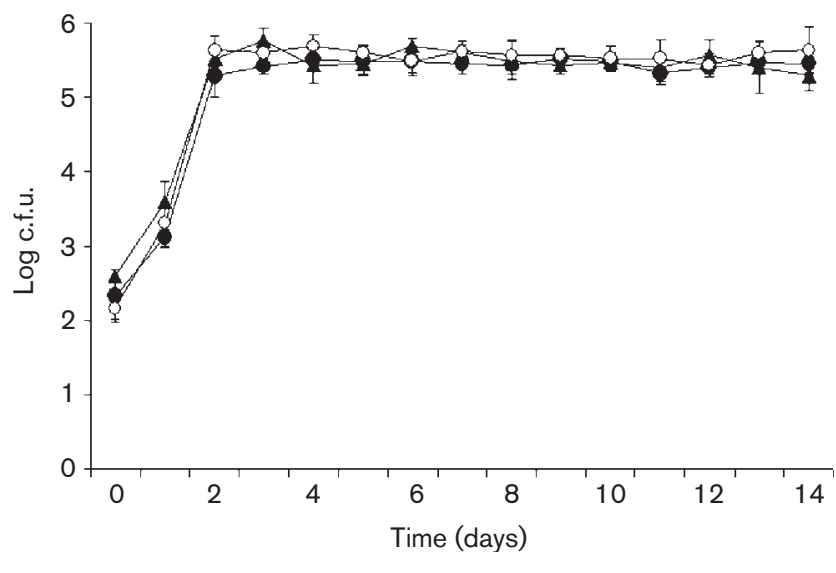

Fig. 4. Intracellular growth and survival of $V$. cholerae. Numbers of intracellular $V$. cholerae strains MO10 ( $)$, MO10-T4 (A) and Bengal-2R ( $)$. The data indicate means $\pm S D$ of three repeated experiments at each time point.

\section{Intracellular localization of $\mathbf{V}$. cholerae M010 strains}

Electron microscopy was used to visualize the intracellular localization of the wild-type MO10, capsule mutant and capsule/LPS double mutant strains in A. castellanii. Samples from co-cultures containing A. castellanii and each $V$. cholerae strain were prepared separately for electron microscopy. The intracellular localization of the bacteria was in the cytoplasm of trophozoites a few hours after co-cultivation (Fig. 5a). Multiplication of bacterial cells occurred in the cytoplasm of trophozoites 1 day after co-cultivation (Fig. 5c, e). Moreover, bacteria were found in the cysts of A. castellanii 6 and 7 days after cocultivation (Fig. 5b, d and f).

\section{DISCUSSION}

Cholera is a severe diarrhoeal disease caused by $V$. cholerae O1 or O139 (Faruque et al., 2005). V. cholerae O1 and O139 can both grow and survive inside A. castellanii, indicating an endosymbiont-host interaction (Abd et al., 2005, 2007; Saeed et al., 2007). However, the involvement of macromolecules in this interaction has not been studied. The present study examined the ability of the clinical isolate V. cholerae MO10 to grow inside A. castellanii and determined the effect of the bacterial capsule and LPS O side chain on the intracellular growth of $V$. cholerae $\mathrm{O} 139$ MO10 in A. castellanii.

The results showed that $A$. castellanii could grow in the presence of $V$. cholerae MO10 strains and the number of amoeba increased 10-fold after 14 days of co-cultivation.

Growth of the bacteria was enhanced in the presence of amoebae compared with growth of bacteria in the absence of amoebae, which decreased to non-detectable levels by 

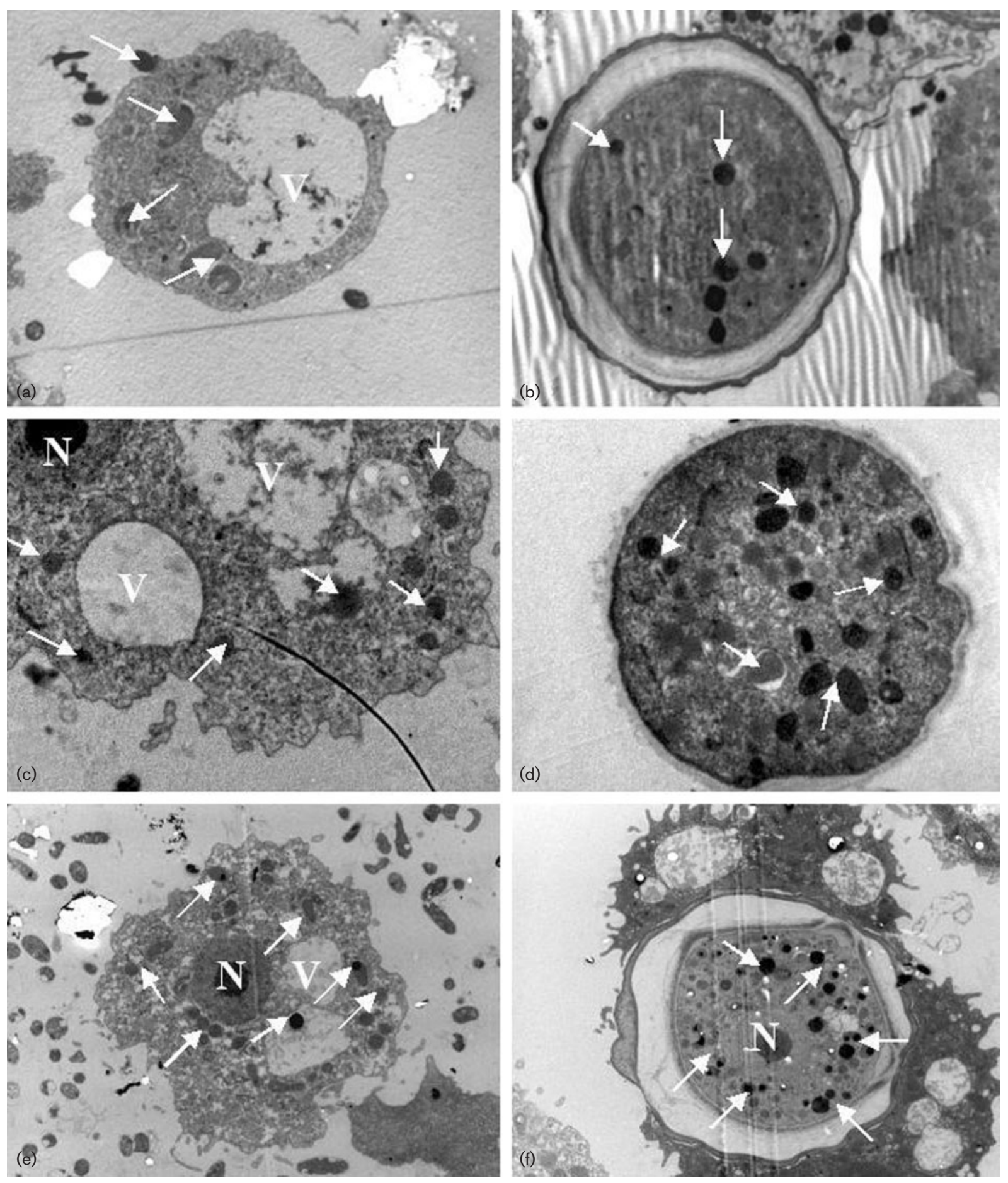

Fig. 5. Electron photomicrographs of the intracellular localization of $V$. cholerae in A. castellanii. (a) A. castellanii trophozoite containing intracellular $V$. cholerae $\mathrm{O} 139 \mathrm{MO} 10$ in the cytoplasm, $3 \mathrm{~h}$ after co-cultivation. (b) $A$. castellanii cyst containing intracellular $V$. cholerae $0139 \mathrm{MO} 10,7$ days after co-cultivation. (c) A. castellanii trophozoite containing intracellular $V$. cholerae MO10-T4 in the cytoplasm, 1 day after co-cultivation. (d) A. castellanii cyst containing V. cholerae MO10-T4, 6 days after co-cultivation. (e) A. castellanii trophozoite containing intracellular $V$. cholerae Bengal-2R in the cytoplasm, 1 day after cocultivation. (f) A. castellanii cyst containing V. cholerae Bengal-2R, 6 days after co-cultivation. Arrows indicate bacteria. N, nucleus; $V$, vacuole. Magnification $\times 3700$. 
days 4-5. In this context, it was confirmed that $V$. cholerae in the absence of amoebae died during the course of the experiment and did not enter a viable but non-culturable state as has been shown previously (Abd et al., 2007).

Growth of the wild-type, capsule mutant and capsule/LPS double mutant strains was enhanced in the presence of $A$. castellanii and the bacteria could grow inside the amoebae. The intracellular growth of the mutant strains was not significantly different from that of the wild-type strain.

Previous studies have shown that both the capsule and LPS $\mathrm{O}$ side chain of $V$. cholerae MO10 enhance adherence to human intestinal mucosa (Alam et al., 1997; Yamamoto et al., 1994) and that the capsule may contribute to partial resistance to phagocytosis (Albert et al., 1999).

In comparison with macrophages, acanthamoebae utilize different mechanisms to capture bacteria by means of specific and non-specific adherence as well as by food-cup formation. It is well known that $A$. castellanii takes up bacteria by pseudopodia to form food vacuoles in which phagocytosis and digestion occur within phagolysosomes (Oates \& Touster, 1976) or by food-cup formation and ingestion of particulate matter (Pettit et al., 1996).

The adherence of bacteria to eukaryotes is the first step in the interaction between the bacterium and the host cell $(\mathrm{Lu}$ \& Walker, 2001). Bacterial adherence to various surfaces includes several methods, including hydrophobic and ionic bonds and lectin-like interactions between bacterial ligands and complementary molecules of the substrate or receptors on eukaryotes (Lock et al., 1987; Tarsi \& Pruzzo, 1999). Lock et al. (1987) found that bacteria possessing mannosesensitive fimbriae were able to adhere to acanthamoebae and leukocytes, and that addition of mannose completely inhibited bacterial adherence to leukocytes, whereas it only partly inhibited adherence to acanthamoebae.

It is thought that expression of fimbriae is influenced by aeration. Our cultivations were done in unshaken flasks. However, aeration also occurs in unshaken flasks, because $\mathrm{CO}_{2}$ is produced by live amoebae by consumption of nutrients in culture medium and disintegration of part of the amoebal cells, as has been observed in interactions between Francisella tularensis and A. castellanii (Abd et al., 2003). Moreover, the culture flask had a filtered cap, which permitted air exchange.

It is known that the mannose-sensitive haemagglutinin fimbria of $V$. cholerae $\mathrm{O} 139$ contributes to its attachment to plankton in aquatic habitats (Chiavelli et al., 2001). In this context, our result showed that the addition of mannose did not affect the adherence to A. castellanii or the uptake and intracellular growth of $V$. cholerae MO10 in $A$. castellanii. This supports the findings by Lock et al. (1987) and may indicate that specific adherence mediated by other factors such as the outer-membrane protein and the toxin co-regulated pilus, as well as non-specific adherence, participate in the interaction between $V$. cholerae and A. castellanii.
In spite of the fact that $V$. cholerae $\mathrm{O} 1 \mathrm{El}$ Tor possesses a mannose-sensitive haemagglutinin fimbria and $V$. cholerae O1 classical does not (Hanne \& Finkelstein, 1982), their intracellular growth in A. castellanii is not significantly different (Abd et al., 2007).

The results showed that the clinical isolate $V$. cholerae MO10 grew and survived symbiotically in A. castellanii over the course of the experiment. The intracellular growth of the wild-type, capsule mutant and capsule/LPS double mutant strains was not significantly different, despite differences in the cell composition of each strain. Moreover, mannose depletion did not inhibit the intracellular growth of wildtype $V$. cholerae MO10 in A. castellanii. Thus $V$. cholerae cells may adhere non-specifically to $A$. castellanii in addition to specific adherence mediated by factors other than mannose.

Acanthamoebae and pathogenic bacteria such as V. cholerae are present worldwide in aquatic environments (Behets et al., 2007), including drinking water (Backer, 2002; Brown \& Barker, 1999; Greub \& Raoult, 2004), and the use of water with poor microbiological quality increases the risk of human illness (Snelling et al., 2006). Acanthamoebae and bacteria are involved in complex interactions important to medical and environmental microbiology. In this context, it may be beneficial to discuss briefly the possible effects of the outcome of the interaction between amoebae and bacteria on health. It is known that acanthamoebae benefit from extracellular bacteria as food (Weekers et al., 1993), which may enhance survival of the amoebae in different environments. In contrast, the role of acanthamoebae as hosts for bacteria has been proposed for many pathogenic bacteria (Abd et al., 2003, 2005, 2007; Alsam et al., 2006; AxelssonOlsson et al., 2005; Barker et al., 1999; Cirillo et al., 1994; Gaze et al., 2003; Jeong et al., 2007; La Scola \& Raoult, 2001; Ly \& Muller, 1990; Steinert et al., 1998; Winiecka-Krusnell et al., 2002). The acanthamoebae support bacterial growth and survival (Saeed et al., 2007) and save the bacteria from the effects of chlorination (King et al., 1988) and antibiotics (Abd et al., 2003, 2005, 2007), increasing the risk of human illness caused by the bacteria or acanthamoebae. Accordingly, a need to find an effective means of killing the intracellular bacteria is warranted under these circumstances, to help reduce the risk of spread of $V$. cholerae and other bacteria.

\section{REFERENCES}

Abd, H., Johansson, T., Golovliov, I., Sandstrom, G. \& Forsman, M. (2003). Survival and growth of Francisella tularensis in Acanthamoeba castellanii. Appl Environ Microbiol 69, 600-606.

Abd, H., Weintraub, A. \& Sandstrom, G. (2005). Intracellular survival and replication of Vibrio cholerae $\mathrm{O} 139$ in aquatic free-living amoebae. Environ Microbiol 7, 1003-1008.

Abd, H., Saeed, A., Weintraub, A., Nair, G. B. \& Sandstrom, G. (2007). Vibrio cholerae $\mathrm{O} 1$ strains are facultative intracellular bacteria, able to survive and multiply symbiotically inside the aquatic free-living amoeba Acanthamoeba castellanii. FEMS Microbiol Ecol 60, 33-39.

Alam, M., Miyoshi, S., Tomochika, K. \& Shinoda, S. (1997). Hemagglutination is a novel biological function of lipopolysaccharide 
(LPS), as seen with the Vibrio cholerae O139 LPS. Clin Diagn Lab Immunol 4, 604-606.

Albert, M. J., Qadri, F., Bhuiyan, N. A., Ahmad, S. M., Ansaruzzaman, M. \& Weintraub, A. (1999). Phagocytosis of Vibrio cholerae O139 Bengal by human polymorphonuclear leukocytes. Clin Diagn Lab Immunol 6, 276-278.

Alsam, S., Jeong, S. R., Sissons, J., Dudley, R., Kim, K. S. \& Khan, N. A. (2006). Escherichia coli interactions with Acanthamoeba: a symbiosis with environmental and clinical implications. J Med Microbiol 55, 689-694.

Axelsson-Olsson, D., Waldenstrom, J., Broman, T., Olsen, B. \& Holmberg, M. (2005). Protozoan Acanthamoeba polyphaga as a potential reservoir for Campylobacter jejuni. Appl Environ Microbiol 71, 987-992.

Backer, H. (2002). Water disinfection for international and wilderness travelers. Clin Infect Dis 34, 355-364.

Barker, J., Humphrey, T. J. \& Brown, M. W. (1999). Survival of Escherichia coli $\mathrm{O} 157$ in a soil protozoan: implications for disease. FEMS Microbiol Lett 173, 291-295.

Behets, J., Declerck, P., Delaedt, Y., Verelst, L. \& Ollevier, F. (2007). Survey for the presence of specific free-living amoebae in cooling waters from Belgian power plants. Parasitol Res 100, 1249-1256.

Brown, M. R. \& Barker, J. (1999). Unexplored reservoirs of pathogenic bacteria: protozoa and biofilms. Trends Microbiol 7, 46-50.

Chiavelli, D. A., Marsh, J. W. \& Taylor, R. K. (2001). The mannosesensitive hemagglutinin of Vibrio cholerae promotes adherence to zooplankton. Appl Environ Microbiol 67, 3220-3225.

Cirillo, J. D., Falkow, S. \& Tompkins, L. S. (1994). Growth of Legionella pneumophila in Acanthamoeba castellanii enhances invasion. Infect Immun 62, 3254-3261.

Dearborn, D. G. \& Korn, E. D. (1974). Lipophosphonoglycan of the plasma membrane of Acanthamoeba castellanii. Fatty acid composition. J Biol Chem 249, 3342-3346.

Faruque, S. M., Naser, I. B., Islam, M. J., Faruque, A. S., Ghosh, A. N., Nair, G. B., Sack, D. A. \& Mekalanos, J. J. (2005). Seasonal epidemics of cholera inversely correlate with the prevalence of environmental cholera phages. Proc Natl Acad Sci U S A 102, 1702-1707.

Gaze, W. H., Burroughs, N., Gallagher, M. P. \& Wellington, E. M. (2003). Interactions between Salmonella typhimurium and Acanthamoeba polyphaga, and observation of a new mode of intracellular growth within contractile vacuoles. Microb Ecol 46, 358-369.

Greub, G. \& Raoult, D. (2004). Microorganisms resistant to free-living amoebae. Clin Microbiol Rev 17, 413-433.

Hanne, L. F. \& Finkelstein, R. A. (1982). Characterization and distribution of the hemagglutinins produced by Vibrio cholerae. Infect Immun 36, 209-214.

Jeong, H. J., Jang, E. S., Han, B. I., Lee, K. H., Ock, M. S., Kong, H. H., Chung, D. I., Seol, S. Y., Cho, D. T. \& Yu, H. S. (2007). Acanthamoeba: could it be an environmental host of Shigella? Exp Parasitol 115, 181-186.

Johnson, J. A., Salles, C. A., Panigrahi, P., Albert, M. J., Wright, A. C., Johnson, R. J. \& Morris, J. G., Jr (1994). Vibrio cholerae O139 synonym Bengal is closely related to Vibrio cholerae El Tor but has important differences. Infect Immun 62, 2108-2110.

King, C. H., Shotts, E. B., Jr, Wooley, R. E. \& Porter, K. G. (1988). Survival of coliforms and bacterial pathogens within protozoa during chlorination. Appl Environ Microbiol 54, 3023-3033.
Knirel, Y. A., Widmalm, G., Senchenkova, S. N., Jansson, P. E. \& Weintraub, A. (1997). Structural studies on the short-chain lipopolysaccharide of Vibrio cholerae O139 Bengal. Eur J Biochem 247, 402-410.

La Scola, B. \& Raoult, D. (2001). Survival of Coxiella burnetii within free-living amoeba Acanthamoeba castellanii. Clin Microbiol Infect 7, 75-79.

Lock, R., Öhman, L. \& Dahlgren, C. (1987). Phagocytic recognition mechanisms in human granulocytes and Acanthamoeba castellanii using type 1 fimbriated Escherichia coli as phagocytic prey. FEMS Microbiol Lett 44, 135-140.

Lu, L. \& Walker, W. A. (2001). Pathologic and physiologic interactions of bacteria with the gastrointestinal epithelium. Am J Clin Nutr 73, 1124S-1130S

Ly, T. M. \& Muller, H. E. (1990). Ingested Listeria monocytogenes survive and multiply in protozoa. J Med Microbiol 33, 51-54.

Nesper, J., Schild, S., Lauriano, C. M., Kraiss, A., Klose, K. E. \& Reidl, J. (2002). Role of Vibrio cholerae O139 surface polysaccharides in intestinal colonization. Infect Immun 70, 5990-5996.

Oates, P. J. \& Touster, O. (1976). In vitro fusion of Acanthamoeba phagolysosomes. I. Demonstration and quantitation of vacuole fusion in Acanthamoeba homogenates. J Cell Biol 68, 319-338.

Pettit, D. A., Williamson, J., Cabral, G. A. \& Marciano-Cabral, F. (1996). In vitro destruction of nerve cell cultures by Acanthamoeba spp.: a transmission and scanning electron microscopy study. J Parasitol 82, 769-777.

Saeed, A., Abd, H., Edvinsson, B. \& Sandstrom, G. (2007). Vibrio cholerae-Acanthamoeba castellanii interaction showing endosymbiont-host relation. Symbiosis 44, 153-158.

Snelling, W. J., Moore, J. E., McKenna, J. P., Lecky, D. M. \& Dooley, J. S. (2006). Bacterial-protozoa interactions; an update on the role these phenomena play towards human illness. Microbes Infect 8, 578-587.

Steinert, M., Birkness, K., White, E., Fields, B. \& Quinn, F. (1998). Mycobacterium avium bacilli grow saprozoically in coculture with Acanthamoeba polyphaga and survive within cyst walls. Appl Environ Microbiol 64, 2256-2261.

Tarsi, R. \& Pruzzo, C. (1999). Role of surface proteins in Vibrio cholerae attachment to chitin. Appl Environ Microbiol 65, 1348-1351.

Waldor, M. K., Colwell, R. \& Mekalanos, J. J. (1994). The Vibrio cholerae $\mathrm{O} 139$ serogroup antigen includes an $\mathrm{O}$-antigen capsule and lipopolysaccharide virulence determinants. Proc Natl Acad Sci U S A 91, 11388-11392.

Weekers, P. H., Bodelier, P. L., Wijen, J. P. \& Vogels, G. D. (1993). Effects of grazing by the free-living soil amoebae Acanthamoeba castellanii, Acanthamoeba polyphaga, and Hartmannella vermiformis on various bacteria. Appl Environ Microbiol 59, 2317-2319.

Weintraub, A., Widmalm, G., Jansson, P. E., Jansson, M., Hultenby, K. \& Albert, M. J. (1994). Vibrio cholerae O139 Bengal possesses a capsular polysaccharide which may confer increased virulence. Microb Pathog 16, 235-241.

Winiecka-Krusnell, J., Wreiber, K., von Euler, A., Engstrand, L. \& Linder, E. (2002). Free-living amoebae promote growth and survival of Helicobacter pylori. Scand J Infect Dis 34, 253-256.

Yamamoto, T., Albert, M. J. \& Sack, R. B. (1994). Adherence to human small intestines of capsulated Vibrio cholerae O139. FEMS Microbiol Lett 119, 229-235. 